\title{
Perancangan Koordinasi Alat Pemberi Isyarat Lalu Lintas (APILL) pada Simpang Jalan PH. H. Mustafa - Jalan Cikutra dan Simpang Jalan PH. H. Mustafa - Jalan Cimuncang
}

\author{
DANIEL FIRDAUS MANURUNG, HERMAN, ANDREAN MAULANA
}

Jurusan Teknik Sipil, Institut Teknologi Nasional, Bandung

Email: Danielfirdaus12@gmail.com

\begin{abstract}
ABSTRAK
Permasalahan yang terjadi di pesimpangan salah satunya adalah antrian kendaraan dan tundaan. Karena itu dibutuhkan sarana dan prasarana yang bekerja dengan baik. Tujuan dari penelitian ini adalah untuk merencanakan koordinasi alat pemberi isyarat lampu lalu lintas pada simpang Jalan PH. H. Mustofa-Jalan Cikutra dan Jalan PH. H. Mustofa-Jalan Cimuncang menggunakan PTV Vissim. Simulasi dilakukan menggunakan 3 kondisi yaitu kondisi eksisting, kondisi terkoordinasi dan kondisi koordinasi - optimasi. Kondisi terkoordinasi dirancang agar saat kendaraan melewati 2 simpang tersebut tidak berhenti dan mengurangi tundaan dan panjang antrian. Hasil simulasi didapatkan bahwa saat dikoordinasikan pada simpang Jalan PH. H. Mustafa-Jalan Cikutra mengalami penurunan tundaan dan antrian. Penurunan terjadi karena kendaraan yang melewati kedua simpang tersebut tidak terhenti akibat sinyal merah. Sedangkan untuk tingkat pelayanan mengalami peningkatan tingkat pelayanan.
\end{abstract}

Kata kunci: simpang, koordinasi, PTV Vissim.

\section{ABSTRACT}

Problems that occur in the intersection of one of them is the queue of vehicles and delays. So it takes facilities and infrastructure that work well. The purpose of this study is to plan the coordination of traffic light signaling equipment at the intersection of Jalan PH. H. Mustofa-Jalan Cikutra and Jalan PH. H. Mustofa-Jalan Cimuncang using PTV Vissim. Simulation is done using 3 condition that is existing condition, co-ordinated condition and coordinated condition - optimization. Coordinated condition while the vehicle is designed to pass through the two intersections did not stop and reduce delays and long queues. the simulation results obtained that when coordinated at the intersection of PH. H. Mustofa street - Cikutra street decreased delays and queues. The decreased because the vehicle passing of two intersection were not stoppep by red signal. As for the level of service has increased the level of service.

Keywords: intersection, coordination, PTV Vissim. 


\section{PENDAHULUAN}

Persimpangan telah menjadi bagian dari sistem transportasi saat ini. Hal ini dapat dilihat di kota besar dengan jumlah penduduk yang tinggi. Akan timbul permasalahan jika semua penduduk Bandung dengan usia produktif bergerak secara bersamaan. Persimpangan pun menjadi bagian yang harus diperhatikan dalam agar dapat melancarkan arus lalu lintas. Oleh karena itu, pesimpangan harus dikelola dengan baik agar kelancaran arus dapat dicapai. Salah satu caranya adalah dengan menghilangkan konflik yang terjadi persimpangan.

Adapun fasilitas yang dapat digunakan adalah lampu lalu lintas (traffic light). Lampu lalu lintas dapat digunakan untuk mengurai konflik di persimpangan. Selain terjadi konflik di persimpangan, terjadi antrian kendaraan yang membuat ruas jalan antara simpang menjadi jenuh dan tidak dapat menampung arus yang masuk dari simpang ke ruas jalan tersebut.

Oleh karena itu, dapat dilakukan perancangan kembali sinyal lalu lintas agar kemacetan dapat terurai dan jalan tersebut tidak mengalami antrian yang panjang. Dalam kasus ini digunakan aplikasi PTV Vissim untuk merancang kembali Alat Pemberi Isyarat Lalu Lintas (APILL).

Tujuan penelitian ini adalah untuk merencanakan koordinasi pada Alat Pemberi Isyarat Lalu Lintas (APILL) menggunakan aplikasi PTV Vissim. Kemudian membandingkan hasil eksisting dan terkoordinasi.

\section{TINJAUAN PUSTAKA}

\subsection{Koordinasi Simpang APILL}

Koordinasi sinyal antar simpang diperlukan untuk mengoptimalkan kapasitas jaringan jalan karena dengan adanya koordinasi sinyal ini diharapkan tundaan (delay) yang dialami kendaraan dapat berkurang dan menghindarkan antrian kendaraan yang panjang. Kendaraan yang telah bergerak meninggalkan satu simpang diupayakan tidak mendapati sinyal merah ada simpang berikutnya, sehingga dapat terus berjalan dengan kecepatan normal (Amelia, 2008 dalam Arouffy, 2002).

Keberhasilan penerapan koordinasi simpang bersinyal ini dinilai dari tercapainya mutu arus lalu lintas yang memenuhi kriteria-kriteria yang menjadi ukuran mutu arus lalu lintas tersebut adalah:

1. Jumlah hambatan (delay).

2. Jumlah waktu tempuh (travel time).

3. Konsumsi energi/bahan bakar.

4. Keselamatan lalu lintas.

5. Dampak lingkungan.

\subsection{Syarat Koordinasi Sinyal}

Pada umumnya, kendaraan yang keluar dari suatu sinyal akan tetap mempertahankan grupnya hingga sinyal berikutnya. Jarak di mana kendaraan akan tetap mempertahankan grupnya untuk sekitar 300 meter (Bayasut 2010 dalam Mcshane 1990 dan Roess 1990), yaitu:

1. Jarak antar simpang yang dikoordinasikan tidak lebih dari 800 meter. Jika lebih dari 800 meter maka koordinasi sinyal tidak akan efektif lagi.

2. Semua sinyal harus mempunyai panjang waktu siklus (cycle time) yang sama atau kelipatannya. 
Perencanaan Koordinasi Alat Pemberi Isyarat Lalu Lintas (APILL) pada Simpang Jalan PH. H. Mustafa - Jalan Cikutra dan Simpang Jalan PH. H. Mustafa - Jalan Cimuncang

3. Umumnya digunakan pada jaringan jalan utama (arteri, kolektor) dan juga dapat digunakan untuk jaringan jalan yang berbentuk grid.

4. Terdapat sekelompok kendaraan (platoon) sebagai akibat lampu lalu lintas di bagian hulu

\subsection{Offset dan Bandwidth}

Offset merupakan waktu (dalam detik) antara permulaan fase lampu hijau disatu persimpangan dengan permulaan lampu hijau di persimpangan berikutnya (Khisty dan Lall, 2003) menurut Bayasut (2010) dalam McShane (1990), memberikan beberapa pengertian offset diantaranya:

1. Perbedaan waktu munculnya sinyal hijau antara dua sinyal bersebelahan.

2. Perbedaan waktu munculnya sinyal merah antaaa dua sinyal bersebelahan.

3. Perbedaan munculnya tengah-tengah hijau antara sinyal bersebelahan.

Menurut Budiman, Pradana dan Ulum (2013) dalam Papacostas (2005), bandwidth adalah perbedaan waktu dalam lintasan pararel sinyal hijau antara lintasan pertama dan lintasan terakhir. Keduanya berada dalam kecepatan yang konstan dan merupakan platoon yang tidak terganggu sinyal merah sama sekali.

\subsection{PTV Vissim}

PTV Vissim adalah program simulasi mikroskopis terkemuka untuk memodelkan operasi transportasi multimodal dan ternasuk dalam perangkat lunak PTV Vissim Traffic Suite. PTV Vissim sekarang digunakan di seluruh dunia oleh sector publik, perusahaan konsultan dan universitas. Selain simulasi kendaraan secara default, PTV Vissim juga dapat digunakan untuk melakukan simulasi pejalan kaki berdasarkan model Wiedemann (fungsi khusus simulasi pedestrian)..

\subsubsection{Parameter Kinerja Simpang PTV Vissim}

Parameter kinerja berikut diadopsi untuk membandingkan hasil keluaran model simulasi data yang diperoleh dari studi lapangan.

1. Waktu tempuh yaitu waktu perjalanan yang dicapai oleh kendaraan yang melaju dengan kecepatan bebas dari lokasi satu (asal) ke lokasi lainnya (tujuan). Satuan waktu tempuh adalah detik atau menit.

2. Panjang antrian kendaraan. Untuk penelitian ini, panjang antrian kendaraan didefinisikan sebagai jarak dalam meter dari garis henti di mana kendaraan mengantri di kaki simpang lampu bersinyal (Yulianto dan Setiono, 2013 dalam Hoque, 1994). Untuk setiap siklus, panjang antrian tercatat pada awal periode hijau. Dalam keadaan ini hanya maksimum panjang antrian yang menjadi perhatian. Terlepas dari lajur di mana hal itu terjadi. Panjang antrian rata-rata yang dihitung selama enam interval untuk perbandingan statistik.

\subsubsection{Kalibrasi dan Validasi}

Kalibrasi adalah proses menyesuaikan parameter untuk mendapatkan nilai yang setara antara nilai simulasi dan nilai yang diamati. Kalibrasi menggunakan metode trial and error. Metode trial and error digunakan untuk proses penyesuian parameter perilaku mengemudi. Validasi adalah pengujian yang dilakukan setelah kalibrasi. Proses pengujian yang dilakukan adalah perbandingan hasil pengamatan di lapangan dengan hasil yang didapat seletah melakukan kalibrasi. Dalam penelitian ini, arus lalu lintas digunakan sebagai pembanding antara hasil pemodelan di PTV Vissim dengan hasil pengamatan di lapangan. 


\section{METODE PENELITIAN}

\subsection{Pengertian Secara Umum}

Secara umum, inti dari metode penelitian adalah untuk menguraikan bagaimana tata cara analisa dan perencanaan yang akan dilakukan. Tujuan dari metode penelitian adalah untuk mempermudah dalam hal pengerjaan agar memperoleh hasil yang baik dan dapat digunakan untuk maksud dan tujuan yang telah ditetapkan.

\subsection{Penjelasan Bagan Alir}

Penelitian dimulai dengan mengidentifikasi masalah yang akan dijadikan bahan untuk penelitian. Setelah mengidentifikasi masalah kemudian mencari studi literatur terdahulu untuk mendapatkan sumber yang tepat untuk dijadikan pedoman dalam pengerjaan penelitian ini. Setelah mendapatkan studi litelatur kemudian dilakukan pengumpulan data berupa data primer dan data sekunder. Data primer berisi volume lalu lintas, waktu sinyal, geometrik simpang, kondisi lingkungan. Sedangkan data sekunder adalah data yang didapat dari instansi lain.

Setelah mendaoatkan data yang dibutuhkan, kemudian melakukan perancangan waktu siklus baru menggunakan aplikasi PTV Vissim. Setelah merancang waktu siklus baru dan mendapatkan hasil kinerja jalan kemudian membandingkan hasil dari PTV Vissim dengan kondisi eksisting. Setelah itu dibuat kesimpulan dari hasil perbandingan tersebut.

\section{PENGOLAHAN DAN ANALISIS DATA}

\subsection{Data Geometrik Simpang}

Data geometrik jalan merupakan data primer yang didapat dari hasil survei. Data geometrik jalan bisa dilihat pada Gambar 1 dan Gambar 2.

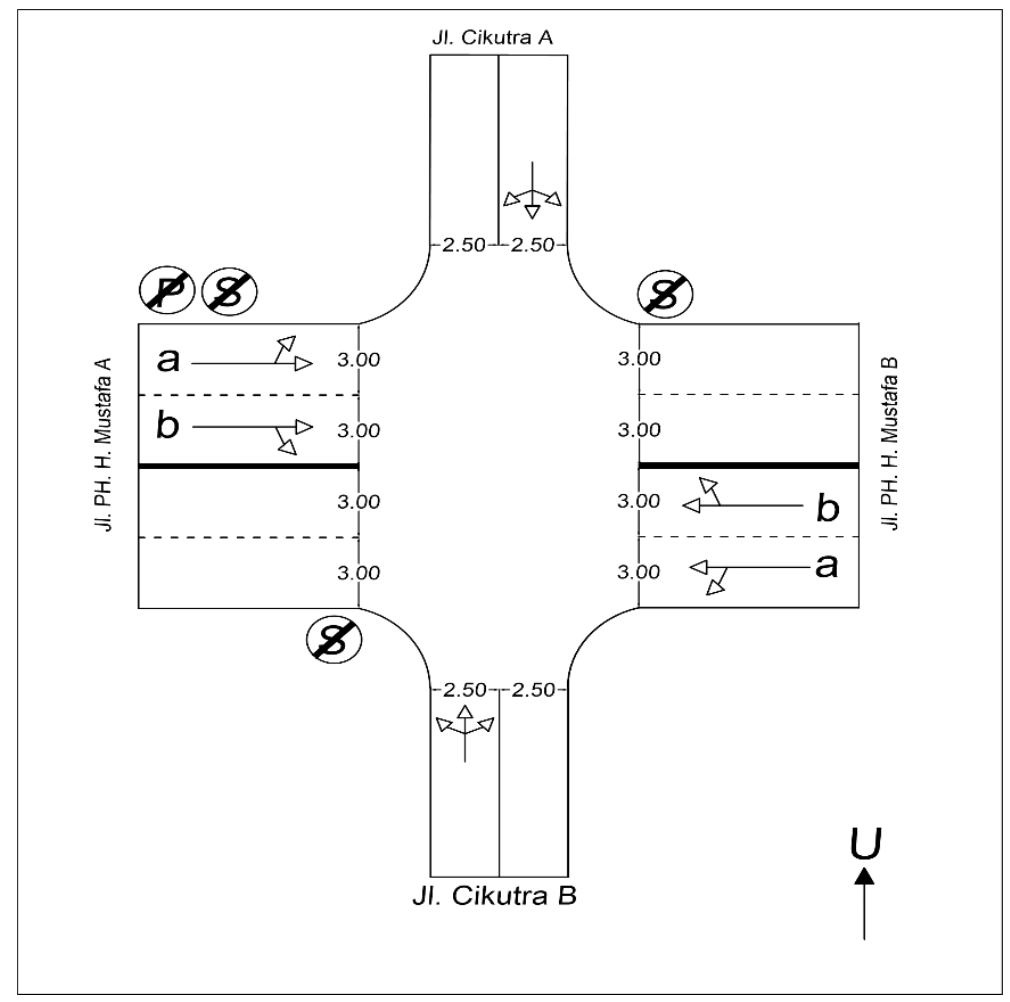

Gambar 1. Geometrik Simpang Jalan PH. H. Mustofa - Jalan Cikutra 
Perencanaan Koordinasi Alat Pemberi Isyarat Lalu Lintas (APILL) pada Simpang Jalan PH. H. Mustafa - Jalan Cikutra dan Simpang Jalan PH. H. Mustafa - Jalan Cimuncang

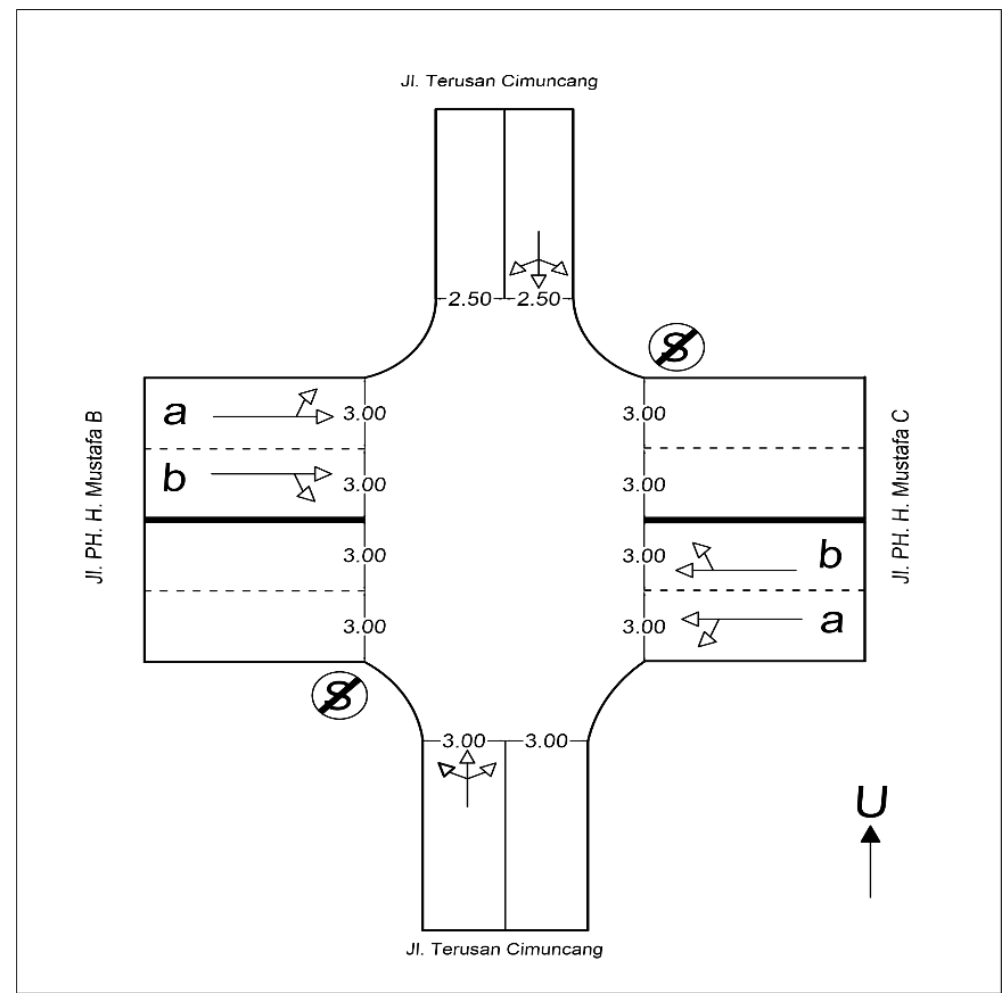

Gambar 2. Geometrik Simpang Jalan PH. H. Mustofa - Jalan Cimuncang

\subsection{Data Volume Lalu Lintas}

Data volume lalu lintas merupakan data primer yang didapat melalui survei selama 1 jam pada ruas jalan yang akan ditinjau. Data volume lalu lintas dapat dilihat pada Tabel 1 dan Tabel 2. Pada Tabel 1 volume lalu lintas pada Jalan $\mathrm{PH}$. H. Mustafa lebih besar dibandingkan dengan Jalan Cikutra A dan Jalan Cikutra B. Pada Tabel 2 volume lalu lintas pada Jalan PH. H. Mustafa lebih besar dibandingkan dengan Jalan Cimuncang dan Jalan Terusan Cimuncang

Tabel 1. Data Volume Lalu Lintas Simpang Jalan PH. H. Mustofa - Jalan Cikutra

\begin{tabular}{|c|c|c|c|c|c|}
\hline \multirow{2}{*}{ Pendekat } & \multirow{2}{*}{ Kendaraan } & \multicolumn{3}{|c|}{ Volume [kendaraan/jam] } & \multirow{2}{*}{$\begin{array}{c}\text { Total } \\
\text { [kendaraan/jam] }\end{array}$} \\
\hline & & Belok Kiri & Lurus & Belok Kanan & \\
\hline \multirow{2}{*}{ Cikutra A } & Kendaraan Ringan (LV) & 132 & 19 & 305 & \multirow{2}{*}{2.144} \\
\hline & Sepeda Motor & 666 & 274 & 748 & \\
\hline \multirow{2}{*}{ PH. H Mustafa } & Kendaraan Ringan (LV) & 282 & 246 & 53 & \multirow{2}{*}{2.246} \\
\hline & Sepeda Motor & 488 & 770 & 407 & \\
\hline \multirow{2}{*}{ Cikutra B } & Kendaraan Ringan (LV) & 46 & 126 & 38 & \multirow{2}{*}{1.850} \\
\hline & Sepeda Motor & 205 & 724 & 711 & \\
\hline
\end{tabular}

Catatan:

$\mathrm{LV}=$ Light Vehicle

Tabel 2. Data Volume Lalu Lintas Simpang Jalan PH. H. Mustofa - Jalan Cimuncang

\begin{tabular}{|c|c|c|c|c|c|}
\hline \multirow{2}{*}{ Pendekat } & \multirow{2}{*}{ Kendaraan } & \multicolumn{3}{|c|}{ Volume [kendaraan/jam] } & \multirow{2}{*}{$\begin{array}{c}\text { Total } \\
\text { [kendaraan/jam] }\end{array}$} \\
\hline & & Belok Kiri & Lurus & Belok Kanan & \\
\hline \multirow{2}{*}{ Terusan Cimuncang } & Kendaraan Ringan (LV) & 67 & 87 & 25 & \multirow{2}{*}{1.9 .14} \\
\hline & Sepeda Motor & 590 & 353 & 792 & \\
\hline \multirow{2}{*}{ PH. H. Mustafa } & Kendaraan Ringan (LV) & 76 & 628 & 51 & \multirow{2}{*}{2.725} \\
\hline & Sepeda Motor & 504 & 1.188 & 278 & \\
\hline
\end{tabular}


Tabel 2. Data Volume Lalu Lintas Simpang Jalan PH. H. Mustofa - Jalan Cimuncang lanjutan

\begin{tabular}{lccccc}
\hline \multirow{2}{*}{ Pendekat } & \multirow{2}{*}{ Kendaraan } & \multicolumn{3}{c}{ Volume [kendaraan/jam] } & \multirow{2}{*}{ Total } \\
\cline { 3 - 5 } & & Belok Kiri & Lurus & Belok Kanan & [kendaraan/jam] \\
\hline \multirow{2}{*}{ Cimuncang } & Kendaraan Ringan (LV) & 145 & 53 & 97 & \multirow{2}{*}{2.158} \\
\cline { 2 - 5 } & Sepeda Motor & 772 & 454 & 637 & \\
\hline
\end{tabular}

Catatan:

LV = Light Vehicle

\subsection{Data Lampu Lalu Lintas}

Data lampu lalu lintas adalah data waktu siklus yang didapat dari hasil survei di lapangan. Data tersebut dapat dilihat pada Tabel 3. Data lampu lalu lintas pada kedua simpang menunjukan bahwa fase 2 waktu antar hijau adalah 0, karena fase 2 merupakan early start dari fase 3.

Tabel 3. Data Lampu Lalu Lintas

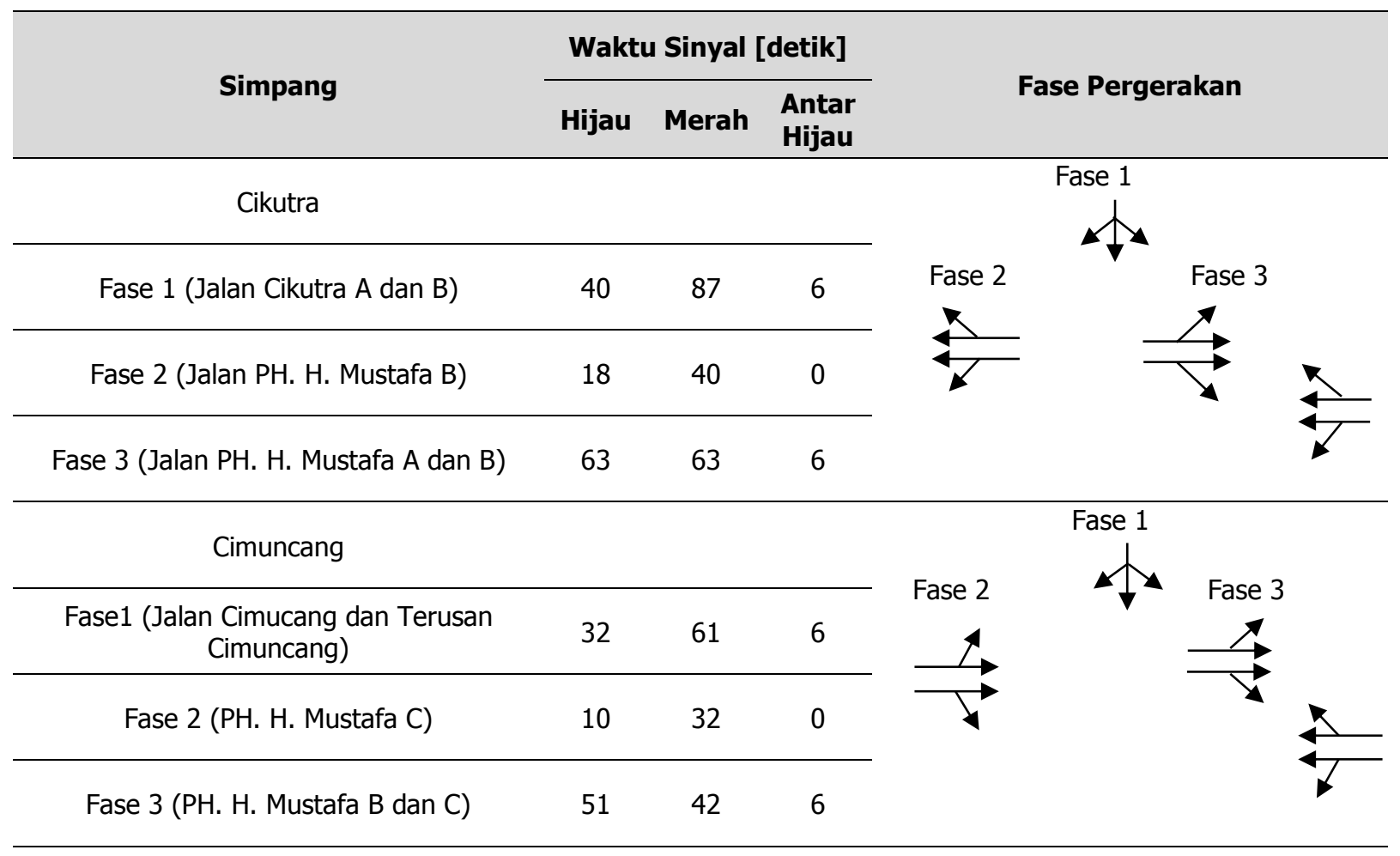

\subsection{Pemodelan Menggunakan Data PTV Vissim}

Tahapan pemodelan menggunakan PTV Vissim adalah menentukan karingan jalan menggunakan link dan connector. Setelah membuat jaringan jalan kemudian memasukan data jenis kendaraan, volume kendaraan, rute perjalanan, kecepatan dan waktu siklus. Setelah itu, melakukan kalibrasi kemudian setelah mendapat hasil dari simulasi kemudian melakukan validasi yang dihitung menggunakan rumus. Setelah itu, melakukan optimasi sinyal yang berguna untuk mencari waktu hijau terbaik tiap simpang. 
Perencanaan Koordinasi Alat Pemberi Isyarat Lalu Lintas (APILL) pada Simpang Jalan PH. H. Mustafa - Jalan Cikutra dan Simpang Jalan PH. H. Mustafa - Jalan Cimuncang

\subsection{Hasil Kalibrasi dan Validasi}

Parameter Kalibrasi yang akan diubah adalah perilaku pengemudi dapat Dilihat pada Tabel 4. Hasil kalibrasi dan validasi bisa dilihat pada Tabel 5. Sebelum dikalibrasi, hasil menunjukan nilai 6,35 sedangkan setelah dikalibrasi menghasilkan nilai 4,94. Hasil kalibrasi dan validasi dapat diterima karena kurang dari 5.

Tabel 4. Parameter Kalibrasi

\begin{tabular}{|c|c|c|c|}
\hline \multirow{2}{*}{ Trial ke - } & \multirow{2}{*}{ Parameter yang Diubah } & \multicolumn{2}{|c|}{ Nilai } \\
\hline & & Sebelum Kalibrasi & Sesudah Kalibrasi \\
\hline \multirow{2}{*}{1} & 1. Desired position at free flow & middle of lane & any \\
\hline & 2. Overtake on same lane: on left \& on right & off & on \\
\hline \multirow{2}{*}{2} & 1. Distance standing at $0 \mathrm{~km} / \mathrm{h}[\mathrm{m}]$ & 1 & 0,2 \\
\hline & 2. Distance driving at $50 \mathrm{~km} / \mathrm{h}[\mathrm{m}]$ & 1 & 0,4 \\
\hline \multirow{3}{*}{3} & 1. Average standstill distance & 0,55 & 0,6 \\
\hline & 2. additive part of safety distance & 0,55 & 0,6 \\
\hline & 3. Multiplicative part of safety distance & 1 & 1 \\
\hline
\end{tabular}

Tabel 5. Hasil Kalibrasi dan Validasi

\begin{tabular}{|c|c|c|c|c|c|}
\hline \multirow{2}{*}{ Kondisi } & \multirow{2}{*}{ Arah } & \multicolumn{2}{|c|}{ Arus Lalu Lintas } & \multirow{2}{*}{$G E H$} & \multirow{2}{*}{ Rata-rata } \\
\hline & & Hasil Simulasi & Lapangan & & \\
\hline \multirow{6}{*}{ Default } & PH. H. Mustafa & 1.971 & 2.246 & 5,99 & \multirow{6}{*}{6,35} \\
\hline & Cicadas & 1.459 & 1.853 & 9,68 & \\
\hline & Cikutra & 1.922 & 2.144 & 4,92 & \\
\hline & Terusan Cimuncang & 1.711 & 2.028 & 7,33 & \\
\hline & Cimuncang & 1.77 & 2.158 & 8,76 & \\
\hline & Sucore & 2.853 & 2.779 & 1,39 & \\
\hline \multirow{6}{*}{ Kalibrasi 6} & PH. H. Mustafa & 2.267 & 2.246 & 0,44 & \multirow{6}{*}{4,96} \\
\hline & Cicadas & 1.918 & 1.853 & 1,50 & \\
\hline & Cikutra & 1.749 & 2.144 & 8,95 & \\
\hline & Terusan Cimuncang & 1.728 & 2.028 & 6,92 & \\
\hline & Cimuncang & 1.78 & 2.158 & 8,52 & \\
\hline & Sucore & 2.962 & 2.779 & 3,42 & \\
\hline
\end{tabular}

\subsection{Hasil Analisis Waktu Sinyal}

Hasil analisis waktu siklus adalah hasil dari pengaturan waktu siklus dengan cara dikoordinasi dan dikoordinasi dengan optimasi bisa dilihat pada Tabel 6. Saat dikoordinasikan, waktu siklus untuk kedua simpang dijadikan sama menjadi 130 detik. Karena untuk mendapatkan waktu offset yang baik serta memenuhi syarat untuk koordinasi sinyal.

Tabel 6. Hasil Analisis Waktu Siklus

\begin{tabular}{lccccccccc}
\hline \multirow{2}{*}{ Simpang } & \multicolumn{7}{c}{ Waktu Sinyal } \\
\cline { 2 - 11 } & \multicolumn{1}{c}{ Eksisting } & \multicolumn{7}{c}{ Setelah Koordinasi } & Setelah Koordinasi dan Optimasi \\
\hline Cikutra & Hijau & Merah & $\begin{array}{c}\text { Antar } \\
\text { Hijau }\end{array}$ & Hijau & Merah & $\begin{array}{c}\text { Antar } \\
\text { Hijau }\end{array}$ & Hijau & Merah & Antar Hijau \\
\hline Fase 1 & 40 & 87 & 6 & 40 & 87 & 6 & 34 & 90 & 6 \\
\hline Fase 2 & 18 & 40 & 0 & 18 & 40 & 0 & 41 & 39 & 6 \\
\hline Fase 3 & 63 & 63 & 6 & 63 & 63 & 6 & 40 & 40 & 6 \\
\hline
\end{tabular}


Tabel 6. Hasil Analisis Waktu Siklus (Ianjutan)

\begin{tabular}{|c|c|c|c|c|c|c|c|c|c|}
\hline \multirow{2}{*}{ Simpang } & \multicolumn{9}{|c|}{ Waktu Sinyal } \\
\hline & \multicolumn{3}{|c|}{ Eksisting } & \multicolumn{3}{|c|}{ Setelah Koordinasi } & \multicolumn{3}{|c|}{ Setelah Koordinasi dan Optimasi } \\
\hline Fase1 & 32 & 61 & 6 & 41 & 80 & 6 & 38 & 63 & 6 \\
\hline Fase 2 & 10 & 32 & 0 & 13 & 41 & 0 & 38 & 48 & 6 \\
\hline Fase 3 & 51 & 42 & 6 & 65 & 53 & 6 & 39 & 42 & 6 \\
\hline
\end{tabular}

\subsection{Hasil Analisis Kinerja Lalu Lintas Menggunakan PTV Vissim}

Hasil analisis yang didapat dari PTV Vissim dapat dilihat pada Tabel 7 dan Tabel 8. Tabel 7 dan Tabel 8 adalah hasil panjang antrian dan tundaan yang terdiri dari hasil Eksisting, koordinasi dan Koordinasi dengan optimasi pada jalan PH. H. Mustafa. Sedangkan untuk Tabel 9 dan Tabel 10 adalah perbandingan penurunan tundaan dan panjang antrian pada kondisi eksisting, koordinasi dan koordinasi dengan optimasi pada Jalan PH. H. Mustafa. Hasil analisis yang didapatkan dari output keluaran PTV Vissim yang telah dikalibrasi dan validasi. Panjang antrian yang terjadi dari 3 kondisi yaitu eksisting, koordinasi dan koordinasi dengan optimasi mengalami kenaikan dan penurunan yang dapat dilihat pada Tabel 9. Hasil analisis tundaan dari kedua simpang adalah hasil dari output dari PTV Vissim. Hasil ini telah melalui proses kalibrasi dan validasi. Hasil perbandingan penurunan dapt dilihat pada Tabel 10.

Tabel 7. Hasil Analisis Panjang Antrian

\begin{tabular}{cccc}
\hline Lengan & Eksisting & $\begin{array}{c}\text { Setelah } \\
\text { Koordinasi }\end{array}$ & $\begin{array}{c}\text { Setelah Koordinasi } \\
\text { dengan Optimasi }\end{array}$ \\
\cline { 2 - 4 } [Meter] & [Meter] \\
\hline Simpang Cikutra & & & 155 \\
\hline PH. H. Mustofa B Lurus B & 149 & 158 & 212 \\
\hline PH. H. Mustofa B Lurus A & 213 & 184 & 212 \\
\hline PH. H. Mustofa B Kiri & 213 & 27 & 37 \\
\hline PH. H. Mustofa B Kanan & 33 & & 104 \\
\hline Simpang Cimuncang & & 36 & 160 \\
\hline PH. H. Mustofa B Lurus B & 94 & 59 & 37 \\
\hline PH. H. Mustofa B Lurus A & 152 & 12 & 160 \\
\hline PH. H. Mustofa B Kanan & 26 & 59 & \\
\hline PH. H. Mustofa B Kiri & 152 & & \\
\hline
\end{tabular}

Tabel 8. Hasil Analisis Tundaan

\begin{tabular}{cccc}
\hline Lengan & Eksisting & $\begin{array}{c}\text { Setelah } \\
\text { Koordinasi }\end{array}$ & $\begin{array}{c}\text { Setelah Koordinasi } \\
\text { dengan Optimasi }\end{array}$ \\
\cline { 2 - 4 } & Detik & Detik & Detik \\
\hline Simpang Cikutra & & 18 & 25 \\
\hline PH. H. Mustofa B Lurus B & 27 & 18 & 33 \\
\hline PH. H. Mustofa B Lurus A & 33 & 27 & 32 \\
\hline PH. H. Mustofa B Kiri & 34 & 10 & 15 \\
\hline PH. H. Mustofa B Kanan & 17 & & 35 \\
\hline Simpang Cimuncang & & 8 & 38 \\
\hline PH. H. Mustofa B Lurus B & 14 & 5 & 29 \\
\hline PH. H. Mustofa B Lurus A & 15 & 2 & 38 \\
\hline PH. H. Mustofa B Kanan & 15 & 7 & \\
\hline PH. H. Mustofa B Kiri & 15 & & \\
\hline
\end{tabular}


Perencanaan Koordinasi Alat Pemberi Isyarat Lalu Lintas (APILL) pada Simpang Jalan PH. H. Mustafa - Jalan Cikutra dan Simpang Jalan PH. H. Mustafa - Jalan Cimuncang

Tabel 9. Hasil Penurunan Panjang Antrian

\begin{tabular}{ccccccc}
\hline Lengan & $\begin{array}{c}\text { Penurunan } \\
\text { Panjang } \\
\text { Antrian Saat } \\
\text { Koordinasi }\end{array}$ & $\begin{array}{c}\text { Penurunan } \\
\text { Panjang Antrian } \\
\text { Saat Koordinasi } \\
\text { dengan } \\
\text { Optimasi }\end{array}$ & $\begin{array}{c}\text { \% } \\
\text { Penurunan } \\
\text { Panjang } \\
\text { Antrian Saat } \\
\text { Koordinasi }\end{array}$ & $\begin{array}{c}\text { \% Penurunan } \\
\text { Panjang Antrian Saat } \\
\text { Koordinasi dengan } \\
\text { Optimasi }\end{array}$ \\
\hline Simpang Cikutra & & & & & & Keterangan \\
[meter] & {$[\%]$} & Keterangan \\
\hline PH. H. Mustofa B Lurus B & 35 & -6 & 24 & Penurunan & -4 & Kenaikan \\
\hline PH. H. Mustofa B Lurus A & 55 & 2 & 26 & Penurunan & 1 & Penurunan \\
\hline PH. H. Mustofa B Kiri & 12 & 2 & 6 & Penurunan & 1 & Penurunan \\
\hline PH. H. Mustofa B Kanan & 5 & -6 & 16 & Penurunan & -19 & Kenaikan \\
\hline Simpang Cimuncang & & & & & & \\
\hline PH. H. Mustofa B Lurus B & 58 & -11 & 61 & Penurunan & -11 & Kenaikan \\
\hline PH. H. Mustofa B Lurus A & 93 & -8 & 61 & Penurunan & -5 & Kenaikan \\
\hline PH. H. Mustofa B Kanan & 15 & -11 & 56 & Penurunan & -40 & kenaikan \\
\hline PH. H. Mustofa B Kiri & 93 & -8 & 61 & Penurunan & -5 & Kenaikan \\
\hline
\end{tabular}

Tabel 10. Hasil Penurunan Tundaan

\begin{tabular}{ccccccc}
\hline Lengan & $\begin{array}{c}\text { Penurunan } \\
\text { Tundaan } \\
\text { Saat } \\
\text { Koordinasi }\end{array}$ & $\begin{array}{c}\text { Penurunan } \\
\text { Tundaaan } \\
\text { Saat } \\
\text { Koordinasi } \\
\text { dengan } \\
\text { Optimasi } \\
\text { [detik] }\end{array}$ & $\begin{array}{c}\text { \% Penurunan } \\
\text { Tundaan Saat } \\
\text { Koordinasi }\end{array}$ & $\begin{array}{c}\text { \% Penurunan } \\
\text { Tondaan Saat } \\
\text { Koordinasi dengan } \\
\text { Optimasi }\end{array}$ \\
\cline { 2 - 8 } Keteterangan & [\%] & Keterangan \\
\hline Simpang Cikutra & & & & & & \\
\hline PH. H. Mustofa B Lurus B & 9 & 2 & 34 & penurunan & 7 & penurunan \\
\hline PH. H.Mustofa B Lurus A & 15 & 1 & 46 & penurunan & 3 & penurunan \\
\hline PH. H.Mustofa B Kiri & 8 & 2 & 22 & penurunan & 6 & penurunan \\
\hline PH. H. Mustofa B Kanan & 7 & 2 & 39 & penurunan & 10 & penurunan \\
\hline Simpang Cimuncang & & & & & & \\
\hline PH. H. Mustofa B Lurus B & 7 & -21 & 46 & penurunan & -149 & Kenaikan \\
\hline PH. H. Mustofa B Lurus A & 10 & -23 & 67 & penurunan & -152 & Kenaikan \\
\hline PH. H. Mustofa B Kanan & 13 & -14 & 86 & penurunan & -92 & Kenaikan \\
\hline PH. H. Mustofa B Kiri & 8 & -22 & 52 & penurunan & -144 & Kenaikan \\
\hline
\end{tabular}

Tingkat pelayanan dapat dilihat dari hasil tundaan rata-rata pada Tabel 11 dan nilai tingkat pelayanan (level of service) dapat dilihat pada Tabel 12. Hasil tingkat pelayanan dapat dilihat pada Tabel 13.

Tabel 11. Tundaan Rata-rata

\begin{tabular}{|c|c|c|c|}
\hline \multirow[t]{2}{*}{ Lengan } & Eksisting & Koordinasi & $\begin{array}{c}\text { Koordinasi dengan } \\
\text { Optimasi }\end{array}$ \\
\hline & Detik & Detik & Detik \\
\hline \multicolumn{4}{|l|}{ Simpang Cikutra } \\
\hline \multicolumn{4}{|l|}{ PH. H. Mustofa B Lurus B } \\
\hline PH. H. Mustofa B Lurus A & \multirow{3}{*}{28} & \multirow{3}{*}{18} & \multirow{3}{*}{25} \\
\hline PH. H. Mustofa B Kiri & & & \\
\hline PH. H. Mustofa B Kanan & & & \\
\hline \multicolumn{4}{|l|}{ Simpang Cimuncang } \\
\hline \multicolumn{4}{|l|}{ PH. H. Mustofa B Lurus B } \\
\hline PH. H. Mustofa B Lurus A & \multirow{3}{*}{15} & \multirow{3}{*}{6} & \multirow{3}{*}{35} \\
\hline PH. H. Mustofa B Kanan & & & \\
\hline PH. H. Mustofa B Kiri & & & \\
\hline
\end{tabular}


Tabel 12. Tingkat Pelayanan (Level of Service)

\begin{tabular}{cc}
$\begin{array}{c}\text { Tingkat } \\
\text { Pelayanan }\end{array}$ & Karakteristik Operasi Terkait \\
\hline A & Kondisi tundaan kurang dari 5 detik perkendaraan \\
\hline B & Kondisi tundaan lebih dari 5 detik sampai 15 detik perkendaraan \\
\hline C & Kondisi tundaan lebih dari 15 detik sampai 25 detik perkendaraan \\
\hline D & Kondisi tundaan lebih dari 25 detik sampai 40 detik perkendaraan \\
\hline E & Kondisi tundaan lebih dari 40 detik sampai 60 detik perkendaraan \\
\hline F & Kondisi tundaan lebih dari 60 detik perkendaraan \\
\hline
\end{tabular}

(Sumber: Kementerian Perhubungan Republik Indonesia, 2015)

Tabel 13. Hasil Tingkat Pelayanan

\begin{tabular}{|c|c|c|c|}
\hline Lengan & $\begin{array}{c}\text { Tingkat } \\
\text { Pelayanan } \\
\text { Eksisting }\end{array}$ & $\begin{array}{c}\text { Tingkat } \\
\text { Pelayanan } \\
\text { Koordinasi }\end{array}$ & $\begin{array}{l}\text { Tingkat Pelayanan } \\
\text { Koordinasi Dan Optimasi }\end{array}$ \\
\hline Simpang Cikutra & & & \\
\hline PH. H. Mustofa B Lurus B & \multirow{3}{*}{ D } & \multirow{3}{*}{$\mathrm{C}$} & \multirow{3}{*}{$\mathrm{D}$} \\
\hline $\begin{array}{c}\text { PH. H. Mustofa B Lurus A } \\
\text { PH. H. Mustofa B Kiri }\end{array}$ & & & \\
\hline PH. H. Mustofa B Kanan & & & \\
\hline Simpang Cimuncang & & & \\
\hline PH. H. Mustofa B Lurus B & \multirow[b]{2}{*}{$\mathrm{C}$} & \multirow[b]{2}{*}{ B } & \multirow[b]{2}{*}{$\mathrm{D}$} \\
\hline $\begin{array}{c}\text { PH. H. Mustofa B Lurus A } \\
\text { PH. H. Mustofa B Kanan } \\
\text { PH. H. Mustofa B Kiri }\end{array}$ & & & \\
\hline
\end{tabular}

Tundaan rata-rata dari tiap kondisi didapat dari penjulahan dari setiap lengan yang dinbagi dengan jumlah lengan simpang. Untuk menentukan tingkat pelayanan (level of service) dilihay dari tundaan rata-rata yang memiliki nilai yang dapat dilihat pada Tabel 12.

\subsection{Pembahasan}

Hasil dari analisis yang dilakukan dengan cara membandingkan tundaan dan panjang antrian dibuat menjad pembahasan, yaitu:

1. Hasil perbandingan penurunan tundaan pada kondisi koordinasi dapat dilihat pada Tabel 10. penurunan tundaan sekitar $22 \%$ - $46 \%$ untuk Simpang Jalan PH. H. Mustofa - Jalan Cikutra dan untuk Simpang PH. H. Mustofa - Jalan Cimuncang terjadi penurunan sebesar $46 \%-86 \%$. Sedangkan untuk keadaan koordinasi dengan optimasi terjadi penurunan tundaan sebesar 3\% - 10\% pada Simpang Jalan PH. H. Mustafa - Jalan Cikutra dan untuk Simpang PH. H. Mustofa - Jalan Cimuncang terjadi kenaikan sebesar 92\% - 149\%

2. Hasil Perbandingan penurunan panjang antrian Pada kondisi koordinasi dapat dilihat pada Tabel 9. Penurunan antrian sebesar $6 \%-26 \%$ untuk Simpang Jalan PH. H. Mustofa Jalan Cikutra pada jalan utama yaitu Jalan PH. H. Mustofa dan untuk Simpang PH. H. Mustofa - Jalan Cimuncang terjadi penurunan sebesar 56\% - 61\%. Sedangkan untuk keadaan koordinasi dengan optimasi terjadi kenaikan panjang antrian sebesar $4 \%-19 \%$ dan penurunan sebesar $1 \%$ pada Simpang Jalan PH. H. Mustafa - Jalan Cikutra. Pada Simpang PH. H. Mustofa - Jalan Cimuncang terjadi kenaikan sebesar 5\% - 40\%

3. Pada Tabel 13 dapat dilihat bahwa tingkat pelayanan untuk Simpang Jalan PH. H. Mustofa - Jalan Cikutra saat kondisi eksisting adalah D sedangkan saat kondisi terkoordinasi adalah C. Untuk Simpang Jalan PH. H. Mustofa - Jalan Cimuncang saat kondisi eksisting adalah C sedangkan untuk kondisi terkoordinasi adalah B. hal ini menunjukan bahwa pada kedua simpang tersebut mengalami kenaikan tingkat pelayanan.

4. Penurunan tundaan dan panjang antrian dikarenakan sebagian besar kendaraan yang melewati 2 simpang yang dikoordinasikan tidak terpengaruh oleh sinyal merah. Sehingga 
Perencanaan Koordinasi Alat Pemberi Isyarat Lalu Lintas (APILL) pada Simpang Jalan PH. H. Mustafa - Jalan Cikutra dan Simpang Jalan PH. H. Mustafa - Jalan Cimuncang

sebagian besar kendaraan dapat melewati simpang tanpa harus terhenti di simpang tersebut.

\section{KESIMPULAN}

Berdasarkan analisis yang telah dilakukan dapat ditarik kesimpulan sebagai berikut:

1. Kedua simpang belum terkoordinasi. Hal ini dapat dilihat dari waktu siklus kedua simpang yang tidak sama dan waktu siklus bukan merupakan kelipatannya. Sehingga tidak memenuhi syarat simpang yang telah dikoordinaasi.

2. Waktu siklus kedua simpang terlebih dahulu disamakan. Waktu siklus yang dipilih adalah 133 detik. Koordinasi dilakukan dengan kecepatan kendaraan $40 \mathrm{~km} / \mathrm{jam}$ sesuai default dari PTV Vissim. Waktu offset yang didapat adalah 67 detik. Dalam hal ini dilakukan pergeseran waktu saat menentukan koordinasi sehingga saat kendaraan lewat simpang tersebut akan mendapat sinyal hijau dari simpang satu ke simpang selanjutnya.

3. Dari hasil analisis didapat dari PTV Vissim dapat dilihat bahwa saat koordinasi terjadi penurunan tundaan dan panjang antrian pada jalan utama pada simpang yang dikoordinasikan. Hal ini dikarenakan sebagian besar kendaraan tidak terpengaruh oleh sinyal merah lampu lalu tersebut adalah jalan PH. H. Mustofa. Sedangkan untuk saat koordinasi dengan optimasi terjadi kenaikan tundaan dan panjang antrian yang diakibatkan karena kedua simpang diptimasi masing-masing. Sehingga, hanya mencari waktu terbaik bagi masing-masing simpang.

\section{DAFTAR RUJUKAN}

Arouffy, M. (2002). Dampak Sistem Sinyal Terkoordinasi Terhadap Biaya. Tugas Akhir - tidak dipublikasikan. Yogyakarta: Universits Gadjah Mada.

Bayasut, E. Z. (2010). Analisa dan Koordinasi Sinyal Antar Simpang Pada Ruas Jalan Diponegoro Surabaya. Tugas Akhir - tidak dipublikasi. Surabaya: Jurusan Teknik Sipil Institut Teknologi Sepuluh Nopember - Surabaya.

Budiman, A., Pradana, M. F., \& Ulum, A. B. (2013). Analisa Simulasi Koordinasi Sinyal Antar Jalan Jendral Ahmad Yani Kota Serang. Jurnal Fondasi, 2 (1), 3.

Hoque, M. (1994). The Modelling of Signalised Intersection in Developing Countries. UK: University of Southamton.

Kementerian Perhubungan Republik Indonesia. (2015). Peraturan Menteri Perhubungan Republik Indonesia Nomor PM 96 Tahun 2015 tentang Pedoman Pelaksanaan Kegiatan Manajemen dan Rekayasa Lalu Lintas. Jakarta: Departemen Perhubungan.

Khisty, C. J., \& Lall, B. K. (2003). Dasar-dasar Rekayasa Transportasi Jilid 1. Jakarta: Erlangga. Papacostas, C. S. (2001). Transportation engineering and planning. New Jersey: Prentice Hall. Roess, R. P., Elena, P. S., \& McShane, W. R. (2004). Traffic Engineering Third Edition. New Jersey: Prentice Hall.

Yulianto, B., \& Setiono. (2013). Kalibrasi dan Validasi Mixed Traffic Vissim Model. Media Teknik Sipil, - (Juli), 3. 